\title{
Solvent-free synthesis of enantioenriched $\beta$-silyl nitroalkanes under organocatalytic conditions
}

\author{
Akhil K. Dubey ${ }^{1}$ and Raghunath Chowdhury ${ }^{*} 1,2, \S$
}

\author{
Full Research Paper \\ Address: \\ ${ }^{1}$ Bio-Organic Division, Bhabha Atomic Research Centre, Trombay, \\ Mumbai 400085, India and ${ }^{2} \mathrm{Homi}$ Bhabha National Institute, \\ Anushaktinagar, Mumbai-400094, India \\ Email: \\ Raghunath Chowdhury* - raghuc@barc.gov.in \\ * Corresponding author \\ § Fax: +91-22-25505151 \\ Keywords: \\ $\beta$-silyl $\alpha, \beta$-unsaturated carbonyl compounds; $\beta$-silyl nitroalkanes; \\ chiral organosilanes; organocatalysis; solvent-free synthesis
}

Open Access

\author{
Beilstein J. Org. Chem. 2021, 17, 2642-2649. \\ https://doi.org/10.3762/bjoc. 17.177
}

Received: 23 August 2021

Accepted: 13 October 2021

Published: 27 October 2021

This article is part of the thematic issue "New advances in asymmetric organocatalysis".

Guest Editor: R. Šebesta

(C) 2021 Dubey and Chowdhury; licensee Beilstein-Institut. License and terms: see end of document.

\begin{abstract}
An enantioselective 1,4-conjugate addition of nitromethane to $\beta$-silyl $\alpha, \beta$-unsaturated carbonyl compounds catalyzed by bifunctional squaramide catalysts has been developed. This methodology offers both enantiomers of $\beta$-silyl nitroalkanes in good to excellent yields (up to $92 \%$ ) and enantioselectivities (up to $97.5 \%$ ee) under solvent-free conditions at room temperature. Control experiments reveal that the presence of a $\beta$-silyl group in the enones is crucial for high reactivity under the optimized reaction conditions.
\end{abstract}

\section{Introduction}

Enantioenriched organosilanes are attractive molecules in organic synthesis owing to their potential applications in stereoselective synthesis $[1,2]$. The unique sterical and electronical features of the $\mathrm{C}-\mathrm{Si}$ bond can induce stereodifferentiation at the adjacent prostereogenic center in organic transformations [2]. In addition, the $\mathrm{C}-\mathrm{Si}$ bond can be oxidized to a hydroxy group by Tamao-Fleming oxidation $[3,4]$ or to an alkene unit via protodesilylation [5,6]. Many complex natural products, bioactive molecules, and drug molecules have been synthesized on exploitation of the above-mentioned properties of organosilanes [2,7-14]. A number of efficient catalytic enantioselective methods has been developed for the synthesis of chiral organosilanes [15-24]. Out of the chiral organosilanes, nitrosilanes are important synthetic targets as they are precursors of valuable $\beta$-aminosilanes [25-27]. Although there is huge success in the synthesis of enantioenriched organosilanes, catalytic routes to synthesize chiral $\beta$-nitrosilanes and in general nitrosilanes have not been well explored. Kobayashi and co-workers realized the synthesis of enantioenriched $\beta$-nitrosilanes through a $\mathrm{Cu}(\mathrm{II})$-chiral bipyridine complex catalyzed enantioselective silyl transfer reaction to nitroalkenes using Suginome's silylboron reagent (Scheme 1a) [28]. Recently, we have reported the synthesis of chiral $\beta$-nitrosilanes via an organocatalytic conjugate addition of nitromethane to $\beta$-silylmethylene 
malonates (Scheme 1b) [29]. As the catalytic enantioselective route is limited to accessible $\beta$-nitrosilanes, there is an urgent need to develop efficient catalytic protocols to deliver enantioenriched $\beta$-nitrosilanes from easily available starting materials.

Metal-catalyzed reaction of various nucleophiles to $\beta$-silyl $\alpha, \beta$ unsaturated carbonyl compounds were documented as one of the straightforward and atom-economic approaches for the facile synthesis of chiral organosilanes (Scheme 1c-f) [30-33] Recently, the aforementioned reaction under organocatalytic conditions has gained attention [34-36]. In this context, Huang, $\mathrm{Fu}$ and co-workers reported carbene-catalyzed enantioselective formal $[4+2]$ annulation reactions of $\beta$-silyl enones with enals and with active acetic esters (Scheme $1 \mathrm{~g}$ ) for the preparation of chiral organosilanes [34-36]. Very recently, during the final stage of our work, the same group disclosed an organocatalyzed conjugate addition of thiols to $\beta$-silyl enones for the synthesis of chiral $\alpha$-mercaptosilanes (Scheme 1g) [36].

As a part of our ongoing program for the development of asymmetric catalytic approaches for the synthesis of enantioenriched organosilanes [29,37,38], we present herein an organocatalyzed conjugate addition reaction of nitromethane to $\beta$-silyl enones to afford chiral $\beta$-silyl nitroalkanes (Scheme 1). Notably, the developed method was not only carried out under solvent-free conditions at room temperature but was found to be tolerant to moisture and air. Therefore, this method offers an attractive and robust option for the preparation of chiral $\beta$-silyl nitroalkanes. In sharp contrast to the aforesaid reaction, organocatalytic conjugate addition reactions of nitroalkanes to enones have been well studied [39-43]. To the best of our knowledge, organocatalyzed or metal-catalyzed enantioselective conjugate additions of nitroalkanes to $\beta$-silyl enones are not yet known.

\section{Results and Discussion}

The optimization study began with the conjugate addition reaction between $\beta$-TMS enone 1a and nitromethane (2) as the model reaction. An uncatalyzed background reaction was not observed while performing the model reaction in toluene as a solvent at $30{ }^{\circ} \mathrm{C}$ for $24 \mathrm{~h}$. To our delight, when the same reaction was carried out in presence of $5 \mathrm{~mol} \%$ catalyst $\mathbf{I}$ in toluene at $30{ }^{\circ} \mathrm{C}$ for $48 \mathrm{~h}$, the desired product 3a was obtained in $84 \%$ yield with $60 \%$ ee (Table 1, entry 1 ). Catalyst II was found to be unproductive as only $25 \%$ conversion of $\beta$-TMS enone 1a was observed (Table 1, entry 2). Gratifyingly, catalyst III furnished product ent-3a in $85 \%$ yield (Table 1, entry 3) with excellent enantioselectivity ( $94 \%$ ee). Whereas catalyst IV gave ent-3a in $85 \%$ yield with slightly lower enantioselectivity ( $91 \%$ ee) as compared to catalyst III (Table 1, entry 4). Catalyst $\mathbf{V}$ also led to product 3a in $66 \%$ yield and $78 \%$ ee (Table 1 , entry 5). Catalyst VI, a pseudoenantiomer of catalyst $\mathbf{V}$ deliv- (i) catalytic asymmetric synthesis of $\beta$-silyl nitroalkanes

(a) Kobayashi (2015) [28]

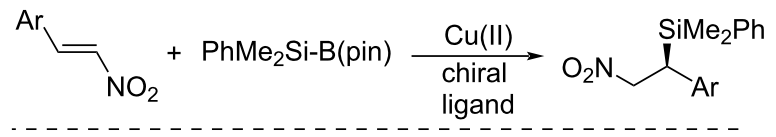

(b) our group (2020) [29]

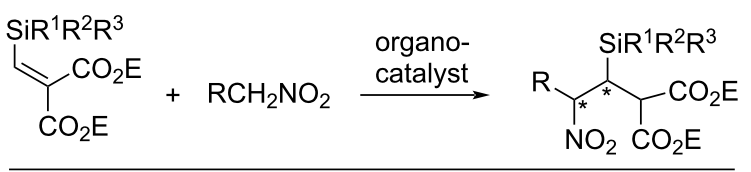

(ii) reactions of $\beta$-silyl enones and acrylate for the synthesis of chiral organosilanes

(c) Hayashi (2005) [30]

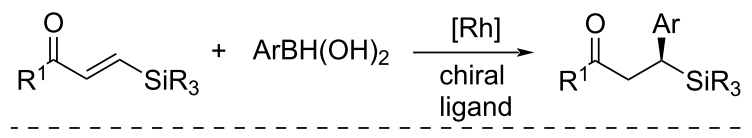

(d) Jacobsen (2006) [31]

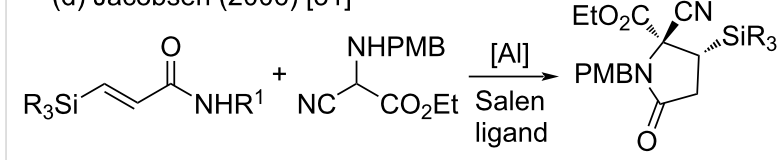

(e) Hoveyda (2007) [32]

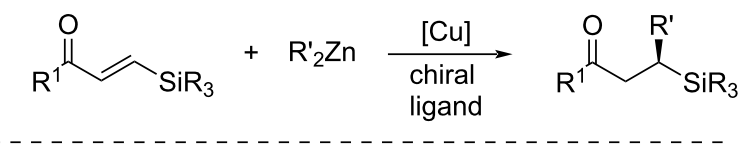

(f) Loh (2014) [33]

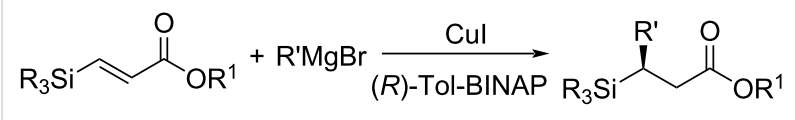

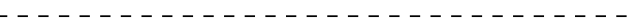

(g) Huang and Fu $(2018,2020$ \& 2021) [34-36]
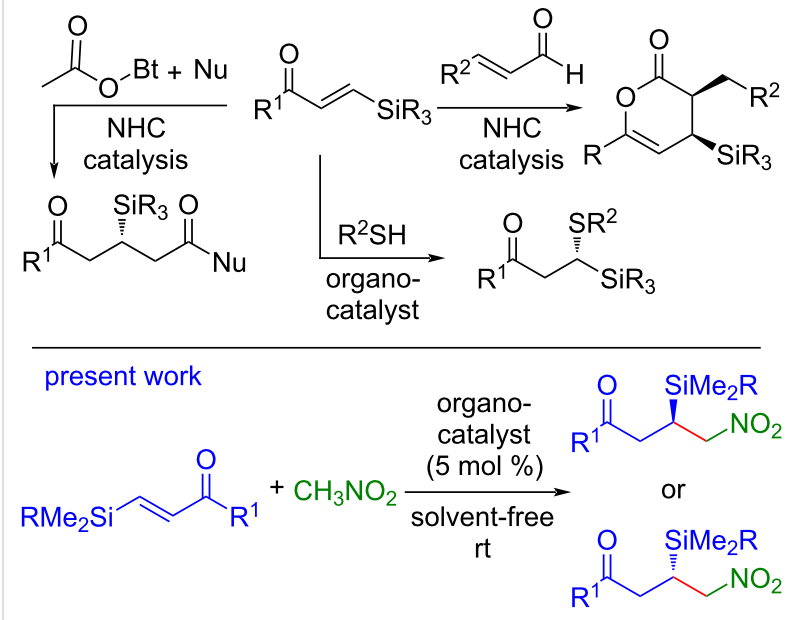

Scheme 1: Selected methods for the synthesis of enantioenriched $\beta$-silyl nitroalkanes, synthesis of chiral organosilanes from $\beta$-silyl $\alpha, \beta$ unsaturated carbonyl compounds, and the present work.

ered ent-3a in $78 \%$ yield with $80 \%$ ee (Table 1, entry 6 ). The catalytic performance of the squaramide catalysts was also explored for the model reaction. Catalyst VII afforded the 
Table 1: Catalysts screening and optimization of reaction conditions. ${ }^{a}$
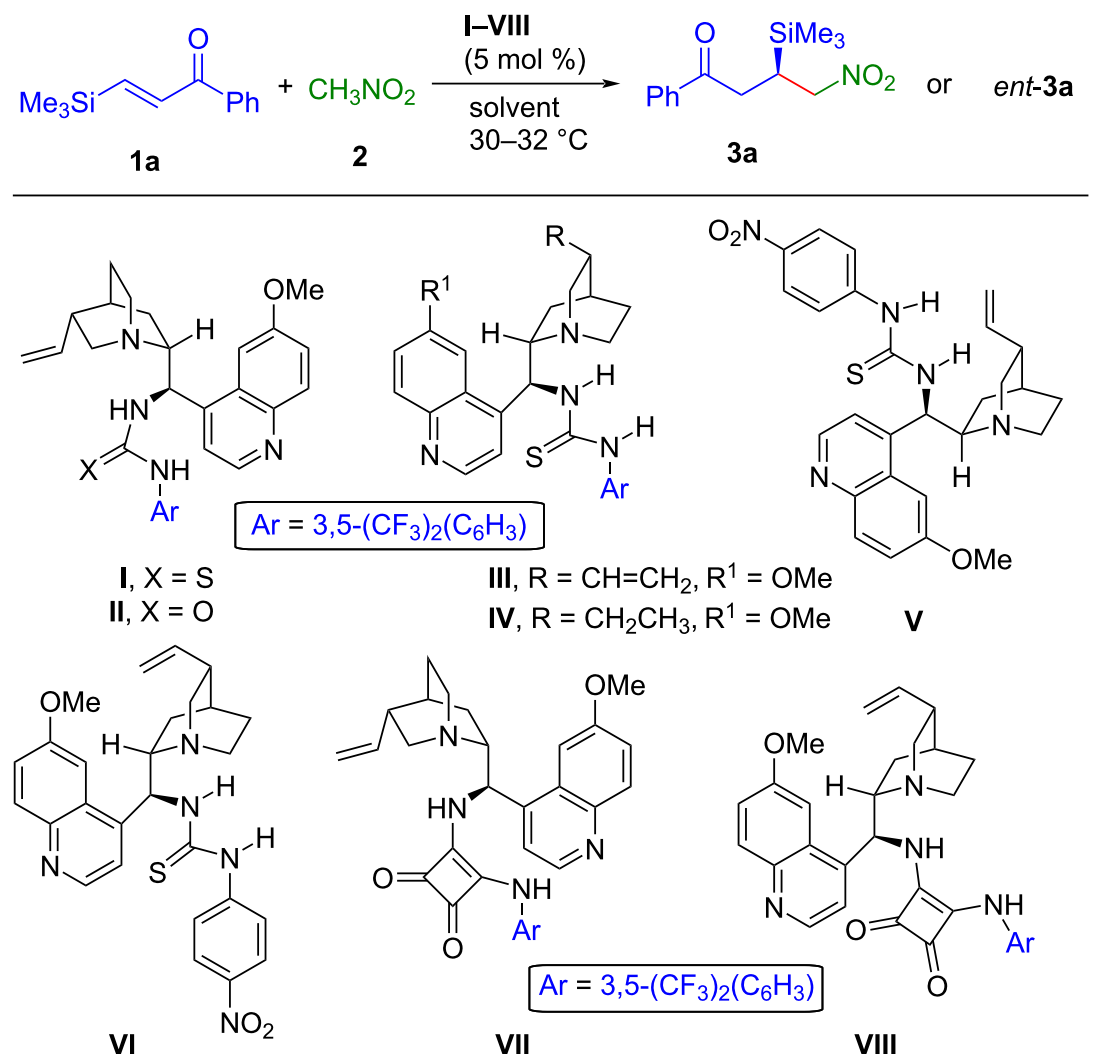<smiles>C=CC1CN2CCC1CC2[C@H](Nc1c(N[Ga])c(=O)c1=O)c1cncc2ccc(OC)cc12</smiles>

$\mathrm{Ar}=3,5-\left(\mathrm{CF}_{3}\right)_{2}\left(\mathrm{C}_{6} \mathrm{H}_{3}\right)$<smiles>C=CC1CC2CCN1C(c1ccnc3ccc(OC)cc13)C2Nc1c(N[Al])c(=O)c1=O</smiles>

VII

VIII

\begin{tabular}{lllllll}
\hline Entry & Cat. & Solvent $(\mathrm{mL})$ & 2a (equiv) & Time $(\mathrm{h})$ & Yield $(\%)^{\mathrm{b}}$ & ee $(\%)^{\mathrm{c}}$ \\
\hline 1 & I & toluene (0.4) & 10 & 48 & $84(98)$ & 60 \\
2 & II & toluene (0.4) & 10 & 48 & ND (25) & ND \\
3 & III & toluene (0.4) & 10 & 48 & $85(>99)$ & $-94^{\mathrm{d}}$ \\
4 & IV & toluene (0.4) & 10 & 48 & $85(>99)$ & $-91^{\mathrm{d}}$ \\
5 & V & toluene (0.4) & 10 & 48 & $66(90)$ & 78 \\
6 & VI & toluene (0.4) & 10 & 48 & $78(97)$ & $-80^{\mathrm{d}}$ \\
7 & VII & toluene (0.4) & 10 & 48 & $78(>99)$ & 97 \\
8 & VII & toluene (0.2) & 10 & 42 & $78(>99)$ & 97 \\
9 & VII & toluene (0.1) & 10 & 24 & $80(>99)$ & 97 \\
10 & VII & - & 10 & 24 & $83(>99)$ & 97 \\
11 & VII & - & 5 & $82(>99)$ & 97 \\
12 & VII & - & 2.5 & 24 & $82(>99)$ & 97 \\
$13^{\mathrm{e}}$ & VII & - & 10 & 24 & $56(85)$ & 97 \\
14 & VIII & - & 2.5 & 24 & $80(>97)$ & $-94^{\mathrm{d}}$ \\
\hline
\end{tabular}

aReaction conditions: $1 \mathrm{a}(0.2 \mathrm{mmol}), 2(0.5-2.0 \mathrm{mmol})$, catalyst $(0.01 \mathrm{mmol}, 5 \mathrm{~mol} \%)$ in toluene or neat at $30-32{ }^{\circ} \mathrm{C}$. ${ }^{\mathrm{b}} / \mathrm{solated}$ yield after column chromatography, \% of conversion of the starting material $1 \mathrm{a}$ is given in parentheses, determined by ${ }^{1} \mathrm{H}$ NMR analysis of the crude reaction mixture. ${ }^{\mathrm{C}}$ Determined by HPLC using a chiralpak OD-H column. ${ }^{\mathrm{d} O p p o s i t e ~ e n a n t i o m e r . ~}{ }^{\mathrm{e}} 2.5 \mathrm{~mol} \%$ of the catalyst VII was used.

conjugate addition product $3 \mathbf{3}$ in $78 \%$ yield with excellent enantiopurity of $97 \%$ ee (Table 1, entry 7). A solvent survey (see Supporting Information File 1 for details) revealed that toluene is the most suitable solvent. Next, we targeted to make the reaction more time economical under mild conditions. For this purpose, the reaction was performed at different concentrations of the reaction mixture (Table 1, entries 8-11). It was observed that time required for completion of the reaction decreased with an increase of concentration of the reaction mixture while the enantiopurity of the product 3a remained unchanged (Table 1, entries 7-9). Next, the model reaction was performed using 10 equivalents of nitromethane (2) in the presence of 
5 mol \% catalyst VII under solvent-free conditions, and was complete within $24 \mathrm{~h}$ without affecting the enantioselectivity of product 3a (Table 1, entry 10). Reducing the loading of nitromethane (2) to 5 equivalents, a slight drop in yield (82\%) of product 3a was observed whereas the enantioselectivity ( $97 \%$ ee) remained the same (Table 1, entry 11 ). Upon further reduction in the loading of nitromethane (2) to 2.5 equivalents, the yield (82\%), enantioselectivity ( $97 \%$ ee), and reaction time were not affected (Table 1, entry 12). Moreover, the reaction became sluggish when conducting the reaction with $2.5 \mathrm{~mol} \%$ of the catalyst VII while keeping other parameters fixed (Table 1, entry 13). Performing the reaction with catalyst VIII, the pseudoenantiomeric catalyst of VII, furnished ent-3a in
$80 \%$ yield and $94 \%$ ee (Table 1, entry 14 ). From the aforementioned studies, compromising slight lower yield of 3a, we set up the optimization conditions as: For 3a, 1a $(0.2 \mathrm{mmol}), \mathbf{2}$ ( $0.5 \mathrm{mmol}$ ), $5 \mathrm{~mol} \%$ of catalyst VII at $30-32{ }^{\circ} \mathrm{C}$ (Table 1 , entry 12) and for ent-3a, 1a $(0.2 \mathrm{mmol}), 2(0.5 \mathrm{mmol}), 5 \mathrm{~mol} \%$ of catalyst VIII at $30-32{ }^{\circ} \mathrm{C}$ (Table 1, entry 14 ).

With the acceptable optimized reaction conditions in hand, we next investigated the generality and limitations of this enantioselective conjugate addition reaction. Under the optimized reaction conditions, the conjugate addition reaction of nitromethane (2) to a variety of $\beta$-silylenones $\mathbf{1}$ was carried out and the results are summarized in Scheme 2. $\beta$-Silylenones bearing electron-<smiles>CO[N+](=O)[O-]</smiles> 
donating, electron-withdrawing groups and halogen substituents in the meta or para position of the phenyl ring reacted smoothly and furnished the desired products $\mathbf{3 a}-\mathbf{k}$ in good to excellent yields (71.5-92\%) and enantioselectivities (76-97.5\% ee). The $\beta$-silylenone with a strong electron-withdrawing group (cyano) attached to the phenyl ring, was found to be most reactive as the reaction completed within $4 \mathrm{~h}$ and afforded the product $3 \mathbf{e}$ in good yield (88\%) and enantioselectivity ( $95.5 \%$ ee). The $\beta$-silylenone with a naphthyl substituent also took part in the conjugate addition reaction and gave the corresponding product $\mathbf{3 j}$ in good yield (83\%) and enantioselectivity $(76 \%$ ee). The reaction also tolerated a 2-thienyl-substituted $\beta$-silylenone and the desired product $\mathbf{3 k}$ was obtained in good yield ( $88 \%$ ) and enantioselectivity ( $97.5 \%$ ee). However, $\beta$-silylbutenone 11 failed to participate in the conjugate addition reaction with nitromethane under the optimized reaction conditions. Pleasingly, using 9-amino-9-deoxyepihydroquinidine (IX)-benzoic acid as organocatalyst system (see Supporting Information File 1 for details) promoted the addition reaction and product $3 \mathrm{I}$ was formed in good yield (79\%) and excellent enantioselectivity ( $99 \%$ ee). The conjugate addition reaction between malononitrile and $\beta$-silylenone 1a was also investigated using $5 \mathrm{~mol} \%$ of catalyst VII under the optimized reaction conditions. To our delight, the reaction completed within $4 \mathrm{~h}$ and the desired product $\mathbf{3 m}$ was isolated in excellent yield $(97 \%)$ with moderate enantioselectivity (52\% ee). $\beta$-Silylenone 2n bearing a $o$-chloro substituent in the aromatic ring remained unreactive under the optimized reaction conditions probably due to steric hindrance.

The facile synthesis of both enantiomers of the targeted compounds is of paramount importance since biological activities are dictated by the absolute configuration of the products. To our delight, catalyst VIII, the pseudoenantiomeric catalyst of VII, allowed to synthesize the enantiomeric products ent-3 (Scheme 3) in high yields and enantioselectivities comparable to the corresponding enantiomers $\mathbf{3}$ under the optimized reaction conditions. The same set of $\beta$-silylenones was explored and an almost similar trend in reactivities, yields as well as enantioselectivities was observed.

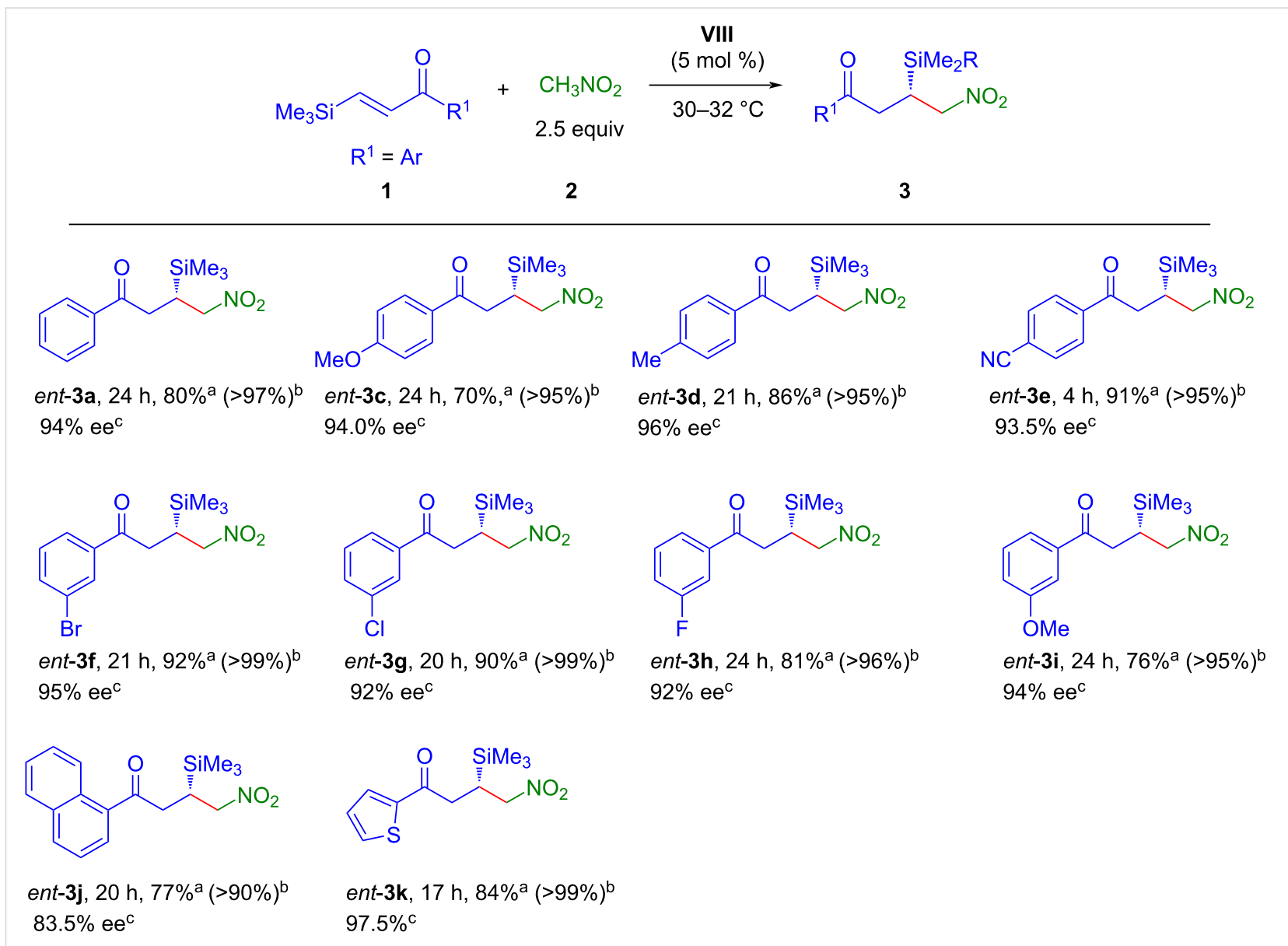

Scheme 3: Synthesis of ent-3. Reaction conditions: $1(0.2 \mathrm{mmol}), 2(0.5 \mathrm{mmol})$, catalyst VIII $(0.01 \mathrm{mmol}, 5 \mathrm{~mol} \%)$ at $30{ }^{\circ} \mathrm{C}$. ${ }^{a} \mathrm{Isolated}$ yield of ent-3 after column chromatography. ${ }^{\mathrm{b}}$ Conversion in \% of the starting material $\mathbf{1}$ is given in the parentheses, determined by ${ }^{1} \mathrm{H}$ NMR analysis of the crude

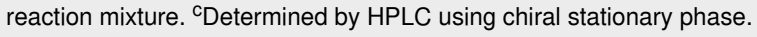


To probe the role of the $\beta$-silyl group, the reaction of tert-butylsubstituted enone $\mathbf{3 o}$ and nitromethane (2) was conducted under the standard reaction conditions using catalyst VII or VIII, affording only trace amounts of products $\mathbf{4}$ or ent-4 even after stirring for $48 \mathrm{~h}$ [44]. When the same reaction was performed in the presence of 10 equivalents of nitromethane using catalyst VII, the product 4 was isolated in $26 \%$ yield and $89.5 \%$ ee after $96 \mathrm{~h}$ whereas the catalyst VIII led to ent-4 in $25 \%$ yield and $95 \%$ ee (Scheme 4 ). This observation confirmed that the presence of the $\beta$-silyl group in the enones played a key role in the high reactivity under the optimized reaction conditions.

The stereochemistry of the silicon-substituted chiral center in compound ent-3k was found to adopt " $(S)$ " configuration which was unambiguously established by single crystal X-ray diffraction analysis (Figure 1) [45].

To prove the scalability of this synthetic method, we examined the synthesis of $\mathbf{3 c}$ and ent-3d in a $1 \mathrm{mmol}$ scale (Scheme 5) The products $\mathbf{3 c}$ and ent-3d were isolated even with better yields while the enantiomeric excess was unperturbed.

\section{Conclusion}

In summary, we have outlined bifunctional squaramidecatalyzed 1,4-conjugate addition reaction of nitromethane

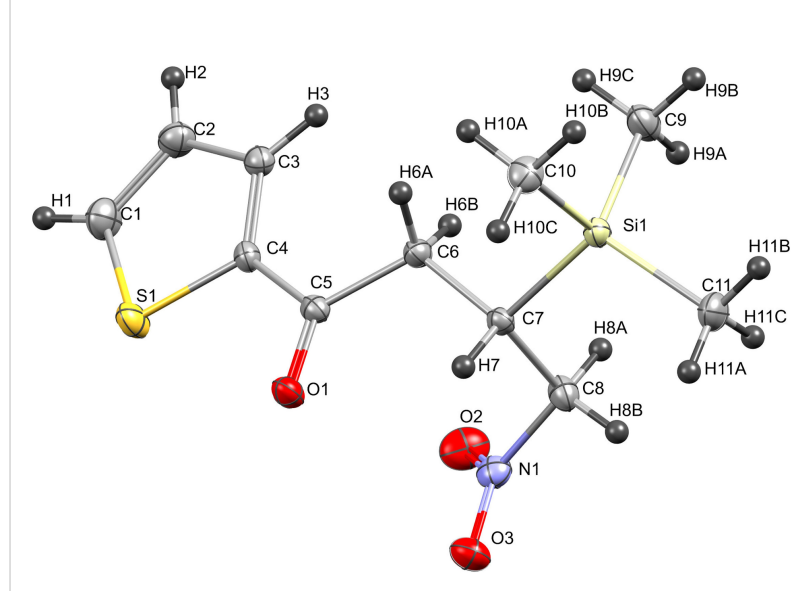

Figure 1: Single crystal X-ray structure of ent-3k (CCDC 2097263).

to $\beta$-silyl $\alpha, \beta$-unsaturated carbonyl compounds to access a series of chiral $\beta$-silyl nitroalkanes in high yields and good to excellent enantioselectivities at room temperature. The notable features of this reaction are access to both the $(R)$ and $(S)$ enantiomers of the products, solvent-free synthesis, mild reaction conditions, low catalyst loading, and use of only a small excess of nitromethane (2.5 equivalents with respect to limiting reagent).

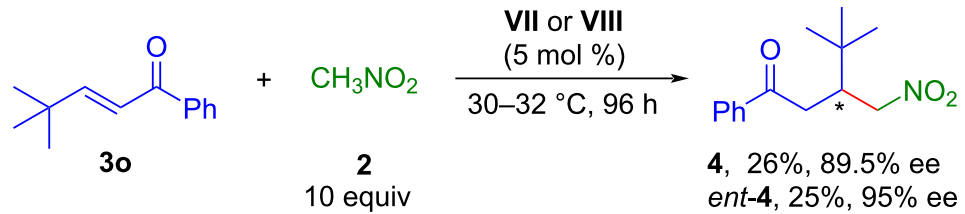

Scheme 4: Organocatalytic 1,4-conjuagte addition of nitromethane (2) to enone 30

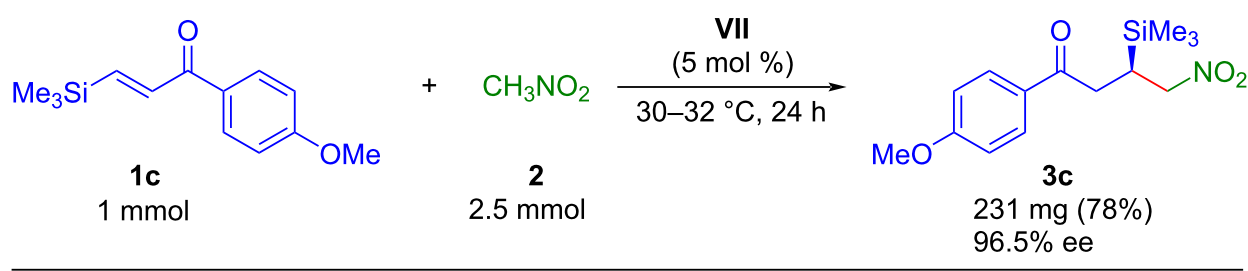<smiles>Cc1ccc(C(=O)/C=C/[SiH3])cc1</smiles>

1d

$1 \mathrm{mmol}$

$$
+\quad \mathrm{CH}_{3} \mathrm{NO}_{2} \underset{30-32^{\circ} \mathrm{C}, 24 \mathrm{~h}}{\stackrel{\text { VIII }}{(5 \mathrm{~mol} \%)}}
$$

2

$2.5 \mathrm{mmol}$<smiles>Cc1ccc(C(=O)CC([SiH3])C[N+](=O)[O-])cc1</smiles>

$96 \%$ ee 


\section{Supporting Information}

\section{Supporting Information File 1}

Experimental data and copies of spectra.

[https://www.beilstein-journals.org/bjoc/content/

supplementary/1860-5397-17-177-S1.pdf]

\section{Acknowledgements}

We are thankful to the National NMR facility, Tata Institute of Fundamental Research, Mumbai for a few NMR measurements.

\section{ORCID ${ }^{\circledR} \mathrm{iDs}$}

Raghunath Chowdhury - https://orcid.org/0000-0002-0395-7014

\section{References}

1. Fleming, I. Sci. Synth. 2002, 4, 927-946. doi:10.1055/sos-sd-004-01012

2. Fleming, I.; Barbero, A.; Walter, D. Chem. Rev. 1997, 97, 2063-2192. doi:10.1021/cr941074u

3. Tamao, K.; Ishida, N.; Kumada, M. J. Org. Chem. 1983, 48, 2120-2122. doi:10.1021/jo00160a046

4. Fleming, I.; Henning, R.; Plaut, H. J. Chem. Soc., Chem. Commun. 1984, 29-31. doi:10.1039/c39840000029

5. Radner, F.; Wistrand, L.-G. Tetrahedron Lett. 1995, 36, 5093-5094. doi:10.1016/0040-4039(95)00948-c

6. Yao, W.; Li, R.; Jiang, H.; Han, D. J. Org. Chem. 2018, 83, 2250-2255. doi:10.1021/acs.joc.7b03139

7. Langkopf, E.; Schinzer, D. Chem. Rev. 1995, 95, 1375-1408. doi:10.1021/cr00037a011

8. Denmark, S. E.; Liu, J. H.-C. Angew. Chem., Int. Ed. 2010, 49 , 2978-2986. doi:10.1002/anie.200905657

9. Fleming, I.; Lawrence, N. J. Tetrahedron Lett. 1990, 31, 3645-3648. doi:10.1016/s0040-4039(00)94466-6

10. Fleming, I.; Ghosh, S. K. J. Chem. Soc., Chem. Commun. 1994, 2287-2288. doi:10.1039/c39940002287

11. Fleming, I.; Lee, D. Tetrahedron Lett. 1996, 37, 6929-6930. doi:10.1016/0040-4039(96)01519-5

12. Lee, J.; Panek, J. S. Org. Lett. 2011, 13, 502-505. doi:10.1021/ol102848w

13. Wu, J.; Panek, J. S. Angew. Chem., Int. Ed. 2010, 49, 6165-6168. doi:10.1002/anie.201002220

14. Pace, V.; Rae, J. P.; Procter, D. J. Org. Lett. 2014, 16, 476-479. doi:10.1021/ol4033623

15. Lee, K.-s.; Hoveyda, A. H. J. Am. Chem. Soc. 2010, 132, 2898-2900. doi:10.1021/ja910989n

16. Mita, T.; Sugawara, M.; Saito, K.; Sato, Y. Org. Lett. 2014, 16, 3028-3031. doi:10.1021/ol501143c

17. Rong, J.; Collados, J. F.; Ortiz, P.; Jumde, R. P.; Otten, E.; Harutyunyan, S. R. Nat. Commun. 2016, 7, 13780. doi: $10.1038 /$ ncomms 13780

18. Sato, Y.; Takagi, C.; Shintani, R.; Nozaki, K. Angew. Chem., Int. Ed. 2017, 56, 9211-9216. doi:10.1002/anie.201705500

19. Duong, H. Q.; Sieburth, S. M. J. Org. Chem. 2018, 83, 5398-5409. doi:10.1021/acs.joc.8b00116
20. Su, B.; Lee, T.; Hartwig, J. F. J. Am. Chem. Soc. 2018, 140, 18032-18038. doi:10.1021/jacs.8b10428

21. Huang, M.-Y.; Yang, J.-M.; Zhao, Y.-T.; Zhu, S.-F. ACS Catal. 2019, 9, 5353-5357. doi:10.1021/acscatal.9b01187

22. Zhu, J.; Chen, S.; He, C. J. Am. Chem. Soc. 2021, 143, 5301-5307. doi:10.1021/jacs.1c01106

23. Zhang, L.; Oestreich, M. ACS Catal. 2021, 11, 3516-3522. doi:10.1021/acscatal.1c00436

24. Kranidiotis-Hisatomi, N.; Yi, H.; Oestreich, M. Angew. Chem., Int. Ed. 2021, 60, 13652-13655. doi:10.1002/anie.202102233

25. Hayama, T.; Tomoda, S.; Takeuchi, Y.; Nomura, Y. Tetrahedron Lett. 1983, 24, 2795-2796. doi:10.1016/s0040-4039(00)88025-9

26. Cunico, R. F. J. Org. Chem. 1990, 55, 4474-4478. doi:10.1021/jo00301a053

27. Jiang, C.-R.; Zhao, C.-L.; Guo, H.-F.; He, W. Chem. Commun. 2016, 52, 7862-7865. doi:10.1039/c6cc03840a

28. Kitanosono, T.; Zhu, L.; Liu, C.; Xu, P.; Kobayashi, S. J. Am. Chem. Soc. 2015, 137, 15422-15425. doi:10.1021/jacs.5b11418

29. Chowdhury, R.; Dubey, A. K.; Ghosh, S. K. Eur. J. Org. Chem. 2020, 2962-2972. doi:10.1002/ejoc.202000306

30. Shintani, R.; Okamoto, K.; Hayashi, T. Org. Lett. 2005, 7, 4757-4759. doi:10.1021/ol051978+

31. Balskus, E. P.; Jacobsen, E. N. J. Am. Chem. Soc. 2006, 128, 6810-6812. doi:10.1021/ja061970a

32. Kacprzynski, M. A.; Kazane, S. A.; May, T. L.; Hoveyda, A. H. Org. Lett. 2007, 9, 3187-3190. doi:10.1021/ol071331k

33. Zhao, K.; Loh, T.-P. Chem. - Eur. J. 2014, 20, 16764-16772. doi:10.1002/chem.201403849

34. Zhang, Y.; Huang, J.; Guo, Y.; Li, L.; Fu, Z.; Huang, W. Angew. Chem., Int. Ed. 2018, 57, 4594-4598. doi:10.1002/anie.201800483

35. Zhang, Y.; Huang, X.; Guo, J.; Wei, C.; Gong, M.; Fu, Z. Org. Lett. 2020, 22, 9545-9550. doi:10.1021/acs.orglett.0c03589

36. Zhang, Y.; Guo, J.; Han, J.; Zhou, X.; Cao, W.; Fu, Z. Org. Biomol. Chem. 2021, 19, 6412-6416. doi:10.1039/d1ob00981h

37. Chowdhury, R.; Dubey, A. K.; Ghosh, S. K. J. Org. Chem. 2019, 84, 2404-2414. doi:10.1021/acs.joc.8b02412

38. Chowdhury, R.; Dubey, A. K.; Ghosh, S. K. Asian J. Org. Chem. 2021, 10, 1173-1183. doi:10.1002/ajoc.202100120

39. Vakulya, B.; Varga, S.; Csámpai, A.; Soós, T. Org. Lett. 2005, 7, 1967-1969. doi:10.1021/ol050431s

40. Wang, J.; Li, H.; Zu, L.; Jiang, W.; Xie, H.; Duan, W.; Wang, W. J. Am. Chem. Soc. 2006, 128, 12652-12653. doi:10.1021/ja065187u

41. Yang, W.; Du, D.-M. Org. Lett. 2010, 12, 5450-5453. doi:10.1021/ol102294g

42. Zhang, G.; Zhu, C.; Liu, D.; Pan, J.; Zhang, J.; Hu, D.; Song, B. Tetrahedron 2017, 73, 129-136. doi:10.1016/j.tet.2016.11.063

43. Cholewiak, A.; Adamczyk, K.; Kopyt, M.; Kasztelan, A.; Kwiatkowski, P. Org. Biomol. Chem. 2018, 16, 4365-4371. doi:10.1039/c8ob00561c

44. The ratio of $30 / 4=90: 10$ (determined by ${ }^{1} \mathrm{H}$ NMR analysis of the crude reaction mixture).

45. The crystallographic data (CCDC 2097263) for ent-3k, can be obtained free of charge from the Cambridge crystallographic Data Centre via http://www.ccdc.cam.ac.uk/data_request/cif. 


\section{License and Terms}

This is an Open Access article under the terms of the Creative Commons Attribution License (https://creativecommons.org/licenses/by/4.0). Please note that the reuse, redistribution and reproduction in particular requires that the author(s) and source are credited and that individual graphics may be subject to special legal provisions.

The license is subject to the Beilstein Journal of Organic Chemistry terms and conditions:

(https://www.beilstein-journals.org/bjoc/terms)

The definitive version of this article is the electronic one which can be found at:

$\underline{\text { https://doi.org/10.3762/bjoc.17.177 }}$ 